\title{
Contemporary Japanese Garden: Modifications of Space and Concealed Meanings*
}

\author{
Nina Konovalova \\ Scientific Research Institute of the Theory and History of Architecture and Urban Planning \\ Branch of the Federal State Budget Institution \\ "Central Scientific-Research and Project Institute of the Construction Ministry of Russia" \\ Moscow, Russia \\ E-mail: phuekirjuko@mail.ru
}

\begin{abstract}
The Japanese garden, which is one of the symbols of the country, was a necessary attribute of traditional Japanese buildings (from a residential building to a temple complex). At World exhibitions, in the improvement of cities of the country, in modern architecture, Japan is looking for new opportunities for harmonious coexistence with natural environment. In twentieth century, feeling influence of the tendency to compact space, the garden, continuing to remain an important element of Japanese culture, is modified, acquiring new types and forms. High density of Japanese cities resulted in unusual architectural and landscape structures: the emergence of vertical, multilayered gardens, and roof gardens. Contemporary garden begins to play rather, a role, an image of the traditional idea of harmony with nature.
\end{abstract}

Keywords-contemporary Japanese garden; gardens in architecture

\section{INTRODUCTION}

Modern conditions of large megalopolises are in a constant contradiction with the natural harmony. The urban environment is changing very quickly, as a result, the living space of citizens is constantly expanding its functions. The result is acceleration and complication, destabilizing life in a modern megalopolis. Gardens are designed to counteract them - traditional and modern, green and dry, they can occupy space inside buildings, in front of them, on their roofs, on the balconies, etc. The shape of the Japanese garden, its location, as well as the space it occupies have undergone serious changes in the late XX - early XXI centuries. However, their artistic and symbolic language has largely retained their traditional features. The importance of gardens for the Japanese culture is so great that various modifications of their space and modern experiments in this area do not contradict traditional canons, but reveal new methods of cultural traditions preservation and actualization.

*The Reported study was Funded by Science and Technology Development State Program of the Russian Federation for years 2013-2020 Program of Fundamental Research of State Academies of Science for years 2013-2020, within the Program of Fundamental Researches of Ministry of Construction, Housing and Utilities of the Russian Federation and Russian Academy of Architecture and Construction Sciences; the Research Project 1.6 .8
The Japanese garden has been perceived as the essential feature of the country for many centuries. Saturated with symbols, embodying the philosophical and aesthetic system of nature understanding as absolute beauty and the model of the universe, the garden in Japan was arranged according to certain rules and supplemented all types of the country's traditional architecture - monasteries, palaces, residential houses, tea rooms, and, perhaps, even more precisely - all of the above have just supplemented the garden.

\section{JAPANESE GARDENS AT WORLD'S FAIRS (EXPO)}

The Japanese garden becomes an obligatory part of each Japanese pavilion at the World Fairs [1]. At the end of the XX - beginning of the XXI century the Expo began to show not only the gardens inherent in the historical tradition (landscape, dry), but also the symbolism of the garden and natural landscape in the elements of architecture. The interior of the Japan pavilion at Expo' 2000 was the allegory of the traditional stone garden. From the gallery of the second tier visitors could see five small sections, called "Islands", which were "scattered" in a huge empty space. Top parts of the "Islands" in their architectural forms resembled natural, unprocessed stones. The internal dynamic of islands' closed spaces is also similar to the traditional symbols of the Japanese rock garden (with its expressive emptiness, the internal interconnection of forms, its asymmetric harmony, expressing the eternity of the world in its infinite variability).

At Expo ' 2005, modern water gardens were presented in addition to traditional ones. They were built using only two elements - water and stones, which have always been the main elements of the Japanese garden. Water is the symbol of negative, feminine, dark, soft Yin power, while stones represent positive, masculine, light and firm Yang power. Their eternal opposition and indissoluble unity expresses the essence of the universe. Visitors of the Expo should feel the essence of Japanese philosophy at the physical and spiritual levels, which the space of the Japanese garden filled with symbols is intended to convey. The focus on its elements leads to the comprehension of the laws of the Universe, to the understanding of man's own nature. The purpose of the contemplation of a Japanese garden lies in the fact that the man stands on the path of transformation: "we must let the 
mind free, leave it on its own. Detachment from ego makes a person free. The truth is in nature" [2].

\section{NEW TYPES AND FORMS OF JAPANESE GARDENS}

Recently, major cities of Japan, as well as all the megacities in the world, have faced the problem of overdensification and the serious shortage of free space. This led to the fact that in the second half of the XX century new forms of houses extremely tiny in size and capsule hotels began to appear in Japan. An acute reduction in space has not spared the gardens. The Japanese, who are perfectly able to embody their artistic genius on small sites, in recent decades have been put in the conditions of almost complete absence of areas for the arrangement of gardens. Due to the high density in old districts of Tokyo, no free space was left for these purposes. But even on very narrow streets, where wooden houses are cramped together and, it seems that there is no way to arrange a garden, people find ways to create them. People put potted plants along the houses, near the doors, on the balconies which infuse the environment with a natural beauty and create shadow, helping to endure the heat of the summer months.

It is appropriate to recall another distinctive feature of Japanese culture - since ancient times, the Japanese have learned to accept what can not be changed, were able to find the most comfortable and productive forms of coexistence with one or another inevitable phenomenon or process. For example, if it is impossible to eliminate the density of population and the construction boom of large cities, Japan has developed "compensatory mechanisms" that can "extinguish" the negative effects of high density. The garden was always one of these "compensatory" mechanisms. By the XXI century gardens in Japan have developed new typologies, meeting the requirements of the time. The main negative factors of modern civilization - the high density of Japanese cities and the fact that the modern urban environment only increases the isolation of a man from nature, led to the introduction of unusual architectural and landscape structures: the creation of vertical, multi-tiered and roof gardens.

Roof gardens in Japanese cities began to rapidly gain popularity in the second half of the XX century. The country's first roof garden was built on the fourth floor of the Grand hotel in Sapporo (1966). A green roof with the area of $660 \mathrm{~m}^{2}$, is decorated with a pond and small "mountains". It is not visible from the street, but almost every room of the hotel has a beautiful view of the garden. Currently roof gardens are already quite common in Japan, they are being arranged on office buildings, residential buildings and even garages.

The tendency to significantly increase the size of the garden shows itself in the greening of the roof. Gardens on the roofs or facades of modern buildings are designed to compensate for the reduction of parks, as well as other green areas and recreational spaces in the cities. The Design for the international reception Hall in Fukuoka Prefecture (ACROS Fukuoka, by "Takenaka Corporation" architectural bureau and Emilio Ambasz) provided the area for the garden on the roof with the area almost two times larger than the footprint of the building itself. This green oasis on the roof is one of a kind. Its concept is the unique combination of urban and park spaces. The North side of the 18-storey building, facing the most prestigious street of the financial district of Fukuoka, is an elegant city facade made of metal and glass. The South facade is almost completely covered with green. It has 15 stepped terraces, which one can climb up to reach the green cascade to the top. Terraced garden virtually expands the space of the Tenjin Park located nearby. This was the main difficulty in discussing the project of the new building - the only empty area in the city center (which was supposed to be given for construction) was located next to the Central Park. Therefore, any high-rise office or an administrative building erected nearby would inevitably create a reduction in the walking area of the Park. And the influx of a large number of people hurrying to work, of course, would destroy the atmosphere of quiet and peaceful walks, which are the main reason to go there for the residents.

The concept of the new building was designed to "invite" seemingly inevitable problems caused by its construction. Green terraces of the ACROS Fukuoka building going upwards on the edge of the park visually even doubled it's size. There are gardens for meditation, relaxation and just hiding from the bustle of the city arranged on each tier of the green cascade. The upper terrace serves as a large belvedere: it offers peerless views of the bay and the surrounding mountains. Waterfalls and swimming pools are created on the terraces to minimize the noise of the business districts of the city. The pools are located directly above the central glass atrium of the building and as a result, soft diffused light penetrates into the interior through the glazed tower separating the pools. In total, there are about 50 thousand plants, occupying an area of $5400 \mathrm{~m}^{2}$ planted on the ledges of this improvised pyramid-park.

There is more than one million square meters of multifunctional space, containing an exhibition hall, a Museum, a theater for 2000 seats, conference rooms, halls and offices of the city administration, as well as retail space and offices located under fifteen Park terraces. The roof garden helps to prevent overheating of the building, maintaining moderate temperature inside. This makes the working environment in the building more comfortable. The roof captures rainwater runoff, supporting the life of plants, insects and birds. The ACROS Fukuoka project with terraces, waterfalls, swimming pools and a huge number of plants embody the idea of a "green" oasis in the center of a big city.

The functions of Japanese roof gardens extend far beyond simple recreation. They are created not only for contemplation and quiet walks, but also for active involvement of inhabitants in collective actions such as holidays, etc. A vivid example is a garden on the roof of the one of high-rise buildings of the Roppongi Hills complex in Tokyo. The rice sowing festival is held there since 2003. In this project, the architect Yoji Sasaki decided to create a special type of public space that people can "discover" for themselves in a big city. A small garden and a rice field are located on the roof of the 45-meter tower, occupying the area of $130 \mathrm{~m}^{2}$. The garden called "The Garden of Rice Fields" gives Tokyo a unique opportunity to experience nature in its 
cycles of life and even become a participant in the regular activities of planting and harvesting rice, as well as cooking rice cakes. This way of communication between people, of course, enriches the culture of the megalopolis and gives a unique opportunity to become a part of one of the oldest Japanese traditions. After all, rice for the Japanese is one of the most essential products, "honsēku" (the main dish of Japanese cuisine). The special attitude to it is evidenced by the ancient tradition, upon which the Emperor and the Empress had to plant rice with their hands, harvest and bring it as a gift to the gods. Even the name that people have given to it is "bodhisattva".

Rice fields are so popular in modern Japanese megalopolises that roofs or the top floor of office buildings are specially given for them. Rice fields on the roofs are not afraid of rain, moreover, they are specially kept flooded to avoid pests and weed growing. Instead of smoke breaks, office workers are allowed to leave their jobs to water "the plantation". It was found that it helps to relieve stress and gain positive emotions. Before the harvest of rice the water is lowered. On the day of the harvest, employees often come with their families and children. This is a real exhilarating and helps to unite the team of the company. It happens that tourists are allowed at the harvest festival. However, for a random person it is very difficult to get to such events. Rice fields on the roofs are not visible for passers-by, and at other times access there is very limited. For example, The "Garden With Rice Fields" of the Roppongi Hills complex can only be seen from the upper floors of the neighboring skyscrapers.

\section{SMALl GARDENS}

However, the over densification of contemporary Japanese cities has led to the spread of very small and tiny gardens. Such microgardens, despite the long history of their existence, got a kind of second birth in the twentieth century. Tsuboniwa - is a very small garden, located within a residential building. Tsuboniwa's were arranged in Zen Buddhist temples, but throughout their history, this type of a garden has been an integral part of the residential architecture space. The earliest mention of tsuboniwa dates back to the Heian period (794-1185), when a small area between the main building of the Palace and residential buildings began to be decorated with plants and flowers. The name of the garden is directly related to its size and comes from two words: units of area, "tsubo", equal to $3.3 \mathrm{~m}^{2}$, and "niwa", meaning "garden, yard", i.e. literally "tsuboniwa" can be translated as a "garden with the area of 1 tsubo". Another translation of the word "tsubo" - a jug, a pot, ie a small container, gives the good idea of how tiny is the space given to this garden.

Tsuboniwa gardens became popular on the empty spaces that have always appeared in the cities between the buildings of Omoteya-Zukuri style ${ }^{1}$, which appeared in Japan in the

The Omoteya-Zukuri style became a standard for traditional townhouses in Japan. It was a group of buildings, usually connected to each other by covered passages. Outside was the street trade shop, it adjoined the dwelling, which went into a courtyard warehouse, workshop and other buildings.
XVI century. Small empty spaces between buildings were necessary for air circulation and natural lighting. In the narrow space between the neighboring houses, the Japanese have created a little universe - the tsuboniwa garden. This tiny garden embodied the philosophy of life and the amazing active desire of the Japanese to live in unity with nature even in crowded urban conditions. Tsuboniwa garden includes all of the traditional elements - bamboo bushes, groups of decorative stones, stone lanterns - and carries a symbolic meaning, forming a natural microcosm. Typically, there have been several (two, and sometimes and three) tsuboniwa's in traditional Japanese homes. Often such garden, even very small, takes on the traditional function of separating the facade of the house from neighboring buildings or, when located inside the building, separating the public areas of the house from residential ones and, of course, becomes a visual barrier (at least symbolic), not allowing to see all of the inner space of the house. In addition, letting fresh air but not bright light inside the house, it traditionally combined architecture with nature, creating the illusion that you are not inside but outside the house.

In modern residential buildings tsuboniwa garden continues to play a significant aesthetic role and has a pronounced functional features. "Ambi-flux house" (arch. A. Yoneda, M. Ikeda), built in Tokyo, had to be built on a tiny piece of land, which made it absolutely impossible to build a yard with a garden, even a very small one. The house, having a minimal footprint, stretched five floors up. The garden was arranged on the balcony of the upper floor and took a tiny area of less than $1 \mathrm{~m}^{2}$. At the entrance to this garden one needs to take off shoes and change them to a specially prepared pair. In a miniature house the garden was a necessary element as a space for relaxation, privacy, contemplation.

\section{DRY GARDEN}

One of the most important types in the tradition of Japanese garden art is a dry garden. Its image and main elements were formed under the influence of Buddhism and the development of temple architecture. A characteristic feature of these gardens, which gave them their name, was the replacement of water with light sand and gravel, which had grooves symbolizing ripples on the water surface. Abstraction and symbolism became the main components of the artistic language of the dry garden, intended primarily for meditation. Zen Buddhism obliges a person to be in power over his emotions and consciousness, calls for strengthening the spirit, understanding the laws of the universe, understanding the truth through self-improvement. Enclosing a certain emotional and semantic potential, the dry garden reveals to each person the opportunity to overcome the low and petty qualities in himself. Zen gardens were no longer intended for walking, their function was similar to landscape scrolls - to help in the practice of contemplation. It's kind of a mandala-garden, created for the generating focused consciousness.

The main elements of the dry garden are untreated stones, arranged separately or in groups. The stone is rightly considered one of the oldest religious symbols of Japan. 
"Driven by the desire to see and feel the invisible mysterious forces of nature and space, a man saw before him the only one substance that arises from the darkness of pristine nature-strong immovable rocks and stones... In natural stones and rocks the man began to see the embodiment of "Mononoke" 2 a symbol that allows you to understand the primordial space" [3]. Back in the Jōmon period, stones and rocks were considered as symbols, holding the spirits of nature and the surrounding space.

The spiritual attraction of the Japanese to raw stones, originally fed by religious beliefs, is characteristic of the entire history of Japan up to the present day. Vast majority of Japanese hotels, restaurants, administrative buildings and mixed-use complexes include dry gardens, sometimes quite tiny in size. One of the biggest Japanese masters in creating Zen gardens is Shunmyo Masuno, which has created more than 40 gardens in Japan and beyond for office buildings, hotels and temples. "The stones have a soul, and they tell me how to use them," Masuno said. [4] A practicing Zen Buddhist priest in the eighteenth generation, he became one of the most famous Japanese landscape architects in the world and became famous for his unique ability to amazingly subtly and accurately combine modern elements with traditional garden symbols. Masuno worked in ultramodern urban hotels and in classic Japanese gardens. And in every project, his work as a landscape architect is inextricably linked to his Buddhist practice.

According to the master, "everyone who finds himself at the Zen garden acquires a special spiritual state leading to awakening, and spiritual awakening can be achieved only by connecting the soul with the mind" [5]. The garden in front of the Tokyo hotel's Azure Tower, created by the master in 2001, consists exclusively of processed stones laid in smooth wavy lines, stepping down to the hotel wall. The garden, built in the spirit of Zen tradition, embodies the image of the sea waves running on a rocky shore. Through a glass wall this garden can be seen by all guests of the hotel, sitting at tables in a cafe or in the guest area located nearby. The creation of stone gardens of high aesthetic value, full of symbolic ambiguity, when several stones can be formed as a sign of the whole universe, is an important part of Japanese traditional garden architecture.

\section{GARDENS AND ARCHITECTURE: “GARDEN OF FINE ARTS"}

Synthesis of architecture and garden art in Japan reached the culmination of its development by the end of the twentieth century, when completely new types of architectural and landscape forms began to appear. They are different in technical, plastic, composite structure from all that was created earlier. "Garden of Fine Arts" has been developed by Tadao Ando in 1994 and occupies an area of 0.3 hectares. The garden's location in Kyoto predetermined the special requirements for this project. It is very difficult to compete with the world-famous gardens of Kyoto, created for concentration and meditation, for admiring the natural

\footnotetext{
"Mononoke", according to the ideas, permeated the nature and all

its phenomena.
}

scenery. Ando found his own, unique version of the garden, developing the idea of a landscape Museum, already embodied by him earlier in Naoshima Contemporary Art Museum [6]. In this case, the idea of Ando reached its climax. The master created both the landscape and gardens exclusively by architectural means. His avant-garde "Garden of Paintings" can be added to the world-famous collection of different types of gardens of the ancient capital of Japan.

The architect designed a three-level concrete structure of the gallery type, suited for contemplation, but not the beauty of nature, but reproductions of the great paintings of outstanding artists from different cultures and eras, which are the part of the world heritage. The main exhibition consists of eight paintings. Here, as in many of his other works, Ando again works on contrasts, creating a synthesis of concrete planes and the natural environment, the strict geometry of forms and intricate trajectories of movement, light and shadow. A three-tier structure received no slabs. The location of the garden in the open air is dictated not only by the desire to convey the ancient laws of garden art, but, above all, the desire to create natural lighting necessary for the correct perception of paintings.

The main part of the garden Museum is located below ground level. This approach helped to preserve the integrity of the botanical garden, located in the neighborhood, and to include its vegetation in the composition of the "Garden of Fine Arts". The viewpoints of the open-air Museum include not only panoramas of green landscapes with rare species of trees, but also the landscape of the Higashiyama mountain, the soft outlines of which were considered the symbol of femininity in Japan since ancient times. It is the architectural use of space in the garden which makes it so popular. A viewer is led through the series of alleys surrounded by concrete and glass panels. The screen with a waterfall passes through all three levels, so the noise of water is heard in the most remote corners of the garden. There are ledges with pools on which water flows at each level of the gallery. The upper, the middle and the lower galleries of the "Garden of Fine Arts" are connected with each other by bridges, paths and passages.

A carefully thought-out plan provides numerous intersections of concrete walls, which led to the complex organization of the garden space. Visitor movement directing with the disclosure of different species perspectives, which Ando loves so much is also clearly visible in this work. With a rather small area of the "Garden of Fine Arts", the visitor who wants to see everything walks miles without noticing it, admiring interesting angles and discovering unexpected turns. This illusion in the formation of space is the distinctive feature of the traditional Japanese garden. It can be called "elongation of space" due to well-created winding paths, which people are led through being, in fact, at the same place. According to the idea of Tadao Ando the movement of people in the space of the "Garden of Fine Arts", is possible only in a spiral that will allow them to go through the entire territory and see the same composition from different points, at different angles. 
The combination of shaded and fully open areas of the garden and the exhibition space is very interesting. The main alleys provided for the movement of visitors are immersed in the shade due to the large overhang of concrete slabs. A person spends most of the time in a pleasant penumbra, because the contemplation of beauty can last forever. The architect understood very well that a comfortable atmosphere is necessary in order to bring to life Zen attitude for selfknowledge through contemplative reflection. From the shaded galleries the visitor gets to the open space, flooded with sunlight. One instinctively wants to stop on such sites because thanks to the artful direction all the attention is brought to the reproductions of the famous paintings exhibited here.

Ando carefully thought out the location of each work and their sequential disclosure to the audience. "Garden of fine arts" is the perfect example of a space created according to the rules and with the spirit of the traditions of Japanese Zen gardens. The basis of the garden was the ancient principle of contemplation, helping to revise everyday ideas about what is the garden, and to return the ability to see the main thing - what the garden has been created for.

\section{CONCLUSION}

At world exhibitions, in the urban design of its cities, in modern architecture, Japan is looking for new opportunities for harmonious coexistence with the natural environment. No other country in the world is characterized by such an attitude towards nature, and its individual components (such as rivers and waterfalls, rocks and stones, forests and individual trees) as the abodes of the divine spirits. The cult of harmony also has not played such a significant role in the culture of any other country of the world. Speaking about the veneration of nature by the Japanese, it should be emphasized that we are not talking about wildlife, which since ancient times has scared the inhabitants of the Japanese Islands, but about nature, enhanced by human hands in a certain way. The garden was created with an intention to skillfully reproduce the surrounding landscape or become a symbol of the universe. The size is not crucial for the Japanese garden. Japanese gardens contribute to the slowdown of time, help to find a pause extremely necessary for every modern man, the purpose of which is still the same as many centuries ago - to restore harmony-with nature, with the world, with oneself.

\section{REFERENCES}

[1] N.A. Konovalova. Japanese architecture at World's fairs // Meet Japan. Moscow, No. 38, 2005, pp. 72-82.

[2] T.P. Grigorjeva. Japan: the way of the heart. - Moscow, 2008. p.30.

[3] K. Tange. The architecture of Japan. Tradition and modernity. Moscow, 1975. p.24.

[4] Landscapes in the spirit of Zen // Process: Architecture, 1995, No. 7. p.10.

[5] Zen Gardens. The complete works of shunmyo masuno. Japan's Leading Garden Designer. N.Y. 2012. p.12.

[6] B. Werner. Tadao Ando, Architecktur der Stille, Architecture of silence. Basel: Birkhäuser, 2001. 